\title{
Democracia y debido proceso. Reflexiones a propósito del trabajo de la Comisión de la Verdad y Reconciliación
}

\author{
Salomón Lerner Febres*
}

Es cierto que, tras las leyes dictadas en el contexto del golpe de Estado de 1992, se produjo el descalabro de las organizaciones terroristas a raíz del encarcelamiento de sus principales dirigentes. No es menos cierto, sin embargo, que en ese mismo proceso miles de peruanos tuvieron que sufrir abusos del Estado, atropellos que, en no pocos casos, se tradujeron en largos años de confinamiento en cárceles inhumanas sin haber cometido delito alguno. Así, pues, un tratamiento integral y honesto del periodo de violencia padecido por nuestro país tiene que preguntarse también si, para acabar con ella, era indispensable someternos a leyes reñidas con el Estado de Derecho; esto es, si para defender la democracia era necesario negar a la misma democracia.

Resulta evidente que todo acto u organización que atente contra el derecho de los peruanos a vivir - $\mathrm{y}$ a vivir en paz- merece nuestro rechazo categórico y sin reservas. Estamos convencidos de que todo Estado democrático está en la obligación de hacer funcionar sus instituciones para defender a sus ciudadanos frente a la agresión de quienes desean sustituir el imperio de la ley por el imperio de la fuerza. Y, sin embargo, si es indiscutible que las democracias tienen el derecho y el deber de defenderse, es igualmente necesario que se tenga siempre presente qué es exactamente lo que defendemos. Se trata, en efecto, de preservar en primer lugar la vida y la integridad humanas. Pero eso no es todo: al defenderse, las democracias deben cautelar una cierta forma de vida plegada a los principios de justicia, equidad, respeto a la persona humana y tolerancia. Protegemos, pues, un arreglo social justo, un régimen de convivencia en el que el respeto a nuestras libertades y a nuestra dignidad de personas y ciudadanos esté siem-

* Ex Presidente de la Comisión de la Verdad y Reconciliación del Perú. Rector Emérito de la Pontificia Universidad Católica del Perú. 
pre garantizado. Entendamos, pues, que las democracias deben defenderse, pero que la peor forma de hacerlo es combatiendo la barbarie con barbarie.

En más de una ocasión se ha afirmado que la democracia, si bien es el más justo de los ordenamientos políticos conocidos, resulta ser, al mismo tiempo, el más débil de ellos, el menos apto para defenderse de quienes la quieren aniquilar. Es una afirmación chocante, pero cierta y no difícil de comprender. En efecto, la razón de ser de toda democracia es otorgar a quienes viven en ella un sistema de libertades, un tejido de garantías y derechos que los proteja de todo abuso del poder. Esas libertades, esas garantías y esos derechos son, inevitablemente, invocados y utilizados en su propio beneficio por quienes, sin creer en ellos ni estar dispuestos a respetarlos, trabajan de manera clandestina o desembozada por derribar un Estado de Derecho. ¿Pero significa esto, acaso, que las democracias deben renegar de sus propios principios para defenderse? Solamente podría pensarlo así quien, a su vez, creyera que las libertades y los derechos son apenas adornos superficiales de la democracia y de la convivencia civilizada. Pero para quienes entiendan que ellos son la sustancia misma de un ordenamiento político justo, dar la espalda a esos principios para preservar el llamado orden público es la peor traición que una democracia puede infligirse a sí misma y el mayor triunfo que puede regalar a sus adversarios.

Entendido esto, resulta muy pertinente reflexionar sobre la justicia, la validez e incluso la eficacia del marco y las prácticas judiciales referidas al terrorismo y la subversión que rigieron en los últimos años. ¿Se puede calificar de justo o siquiera de eficaz un sistema que, si por un lado condenó y dispuso la merecida reclusión de muchos culpables, por otro lado deparó el mismo destino a centenares de inocentes? ¿Cómo entender que el mismo Estado que emitió condenas severísimas haya debido constituir una comisión ad hoc de indultos y que esta encontrara, en tres años y medio de trabajo, casi seiscientos presos inocentes de todo delito. Para entender y adoptar una perspectiva adecuada frente a esos contrasentidos, debemos, en principio, emanciparnos de la ideología de la seguridad del Estado entendida como un fin supremo al que se pueden subordinar incluso los derechos humanos, esa expresión jurídica de las facultades y libertades que nos permiten acceder a una vida racional, justa y, sobre todo, digna. Cuando en una sociedad se permite que la seguridad del Estado prevalezca sobre los derechos de las personas, cuando se llega a concebir el orden público como un bien superior y distinto de las libertades de los ciudadanos, estamos hablando de una democracia que, en cierto modo, ya ha sido parcialmente derrotada por sus adversarios, pues ha consentido, tal vez sin advertirlo, en identificarse con los métodos y con los principios, o para ser más exactos, con la carencia de principios de aquellos. 
El reto de la justicia dentro del sistema democrático es, pues, sumamente delicado, y a propósito de él es necesario analizar si nuestras instituciones y nuestros gobernantes supieron estar a la altura de ese reto. La respuesta que se nos ofrece no es alentadora: no lo estuvieron - no lo estuvimostoda vez que aceptamos como forma de defensa métodos concebidos desde la perspectiva reductora y excluyente de la seguridad del Estado, procedimientos que, desde su nacimiento, se advirtieron reñidos con principios que atañen a los derechos humanos más elementales.

En el Perú se instauró -y así lo comprobó la CVR - un marco jurídico y, más precisamente, un régimen penal, divorciado de principios básicos como el de la legalidad, que prohíbe la implantación de leyes que impliquen la violación de derechos humanos. En el clima de zozobra de los años ochenta y noventa, el poder político impuso formas de procedimiento judicial que vedaron a los acusados el ejercicio de su derecho al debido proceso y, dentro de él, su derecho a la defensa. Una justicia expeditiva, que respondía al temor generalizado con sentencias veloces impuestas a personas que en muchos casos no entendían de qué delito se les acusaba, terminó por dejarnos en manos de la arbitrariedad y el abuso, esas negaciones mismas de la justicia que por lo demás - como bien sabemos- suelen encarnizarse en nuestro país con la población más débil, más pobre y más privada de consideración social, esa misma población que ya resultaba ser víctima mayoritaria de la violencia que azotaba nuestro país. Y solo por redondear una síntesis muy modesta de esta extensión de la violencia que fue nuestro sistema judicial, recordemos el olvido de otro principio básico del buen ejercicio del derecho: la necesaria correspondencia entre la pena y la gravedad del delito, principio sustituido entre nosotros por una imposición de penas en muchos casos desproporcionadas, práctica que, si bien parecía responder en ese momento a un clamor de la población, estuvo siempre reñida - y lo está todavía - con el orden democrático que aspiramos a cultivar y hacer arraigar en nuestro país.

Debemos entender, pues, que el Perú ha vivido bajo un estado de negación de la justicia, entendida esta en su recto sentido. La justicia no es un valor etéreo que se agota en una definición abstracta o ideal. La justicia, si es justicia humana, vive y encarna en su aplicación práctica, en su administración por los hombres y mujeres que asumen como tarea y obligación la función jurisdiccional. Ese valor que llamamos justicia no se confunde con la práctica judicial, pero tampoco puede existir sin ella. De allí que, cuando los caminos que se siguen para que la justicia resulte eficaz no son los adecuados, el valor mismo sufre un deterioro, una tergiversación, y ello se expresa en el sufrimiento de seres concretos, en personas que ven atropellados sus derechos y en el deterioro de la vida ciudadana en toda la sociedad. De 
ser ciudadanos libres y dotados de derechos, nos convertimos, todos, en sospechosos, en acusados potenciales obligados a demostrar su inocencia frente a jueces y fiscales que, desconociendo la naturaleza misma de su vocación, dejan de ser defensores de nuestros derechos para convertirse en sus agresores.

Quienes administran justicia pueden reclamarse titulares de esa importante función en tanto que la sociedad les ha conferido la facultad de juzgar. Pero despojemos por un momento a esta palabra - juzgar - de su acepción estrictamente forense para considerar sus raíces y sus resonancias filosóficas. Juzgar no es, en efecto, lo mismo que sentenciar. Quien juzga, es decir, quien pone en práctica su capacidad de juicio, no ha de ser un sujeto únicamente orientado a producir una sentencia. Su materia y su misión son más elevadas y complejas. El que juzga pondera alegatos, hechos y circunstancias, aprecia argumentos e informaciones, valora las pruebas e indicios que se le ofrecen, busca los nexos lógicos entre los retazos de evidencia que ha conseguido; en suma, quien juzga, antes que condenar, quiere llegar a la verdad, una verdad que no puede emanar sino de la recta apreciación de los hechos y las circunstancias.

Queremos, pues, rescatar una comprensión más humana de la justicia. Ella no puede consistir en esa maquinaria ciega y superior a las realidades de las personas y a los hechos que ponen en marcha los Estados antidemocráticos para deshacerse de sus enemigos. Los países que aman la democracia han sabido crear en las últimas décadas un sistema internacional de derecho mediante convenios, acuerdos, tratados, cuyo objetivo último es asegurar que los Estados, al defenderse, lo hagan respetando - es decir, defendiendo a su vez- a sus ciudadanos que son su razón de ser, su fin último, como declaran diversas constituciones. El Perú es -y lo recordamos con orgullo y con esperanza- signatario de muchos de esos tratados y por ello es su obligación adecuar su legislación a esos criterios básicos de humanitarismo y derecho a la integridad y la dignidad de la persona adoptados por la comunidad internacional.

Ahora bien, ¿es posible luchar desde la democracia y, por tanto, en un marco de juridicidad impecable, contra quienes buscan, precisamente, derribar la democracia? Hemos de reconocer que es una pregunta sumamente difícil de contestar. Pero respondemos a ella, con claridad, que no solo es posible hacerlo así, sino que esa es, en rigor, la única forma en que una democracia puede defenderse y salvarse. Adoptar los métodos de la barbarie, como hemos dicho, es la peor de las derrotas para una democracia: esa clase de derrota que nos llega disfrazada de éxito, una derrota moral y espiritual, una derrota que nos infligimos a nosotros mismos. 
En la CVR, al sostener estos puntos de vista, éramos concientes de que, al abordar este tema, estábamos encarando una cuestión sumamente compleja y espinosa que afectaba nuestra sensibilidad y, en especial, la de quienes fueron directamente dañados por atentados $u$ otras formas de agresiones a sus derechos elementales durante los años de la violencia. A ellos quisimos decirle entonces - queremos decírselo ahora - que no estábamos hablando ni propiciando la indulgencia frente a quienes comprobadamente fueron responsables de afectar la vida o la integridad física de los peruanos; más bien, estábamos pensando en aquellos compatriotas nuestros que, sin haber cometido delito, fueron injustamente condenados, en aquellos que no tuvieron el derecho a defenderse, en aquellos que no pudieron acceder a un proceso judicial justo como aquel al que todos los ciudadanos de este país tenemos derecho.

La Comisión de la Verdad y Reconciliación tuvo el deber de examinar con franqueza el proceso vivido y hablar con claridad a los peruanos sobre lo que ocurrió en esos años. No hubiéramos cumplido con nuestro cometido, ni honrado nuestro compromiso, si hubiéramos eludido algún aspecto de ese proceso por consideraciones de oportunidad política o por creer que la sociedad peruana no estaba preparada para afrontarlo. Hemos afirmado en más de una ocasión que el autoexamen que nuestra sociedad debía realizar era arduo y complejo, y la ciudadanía, al expresarnos de diversas maneras su respaldo, nos autorizó a llevarlo adelante. Por ello, tenemos la seguridad de que el tema que hoy aún se discute será, por fin, rectamente entendido y ponderado y que, fruto de esa comprensión, de ese examen colectivo, será el avance hacia la consolidación de una sociedad justa y democrática.

Vivimos en un mundo acosado por múltiples conflictos, desfigurado por innumerables atropellos, por el empleo abusivo de la fuerza de los Estados contra las personas que deberían defender. La CVR quiso, con su trabajo, alentar una introspección colectiva por parte de los peruanos y, además, quiso también enviar un mensaje a la comunidad internacional: no es posible combatir la barbarie sin hacerse eco de la barbarie; no es admisible defender nuestras democracias mediante una renuncia al Estado de Derecho. La experiencia que vivimos los peruanos es, en cierto modo, la derrota ante el reto de defender la democracia en democracia, de defender la ley con el respeto irrestricto a la ley. No supimos vencer ese desafío, y el precio de ese fracaso lo pagaron - lo siguen pagando- muchos ciudadanos humildes. Es nuestra tarea, por tanto, poner nuestra inteligencia, nuestra imaginación, al servicio de una búsqueda inaplazable: el camino para defender nuestro Estado de Derecho sin traicionarlo. Es, por cierto, una búsqueda difícil, que nos hará transitar por territorios inciertos y resbaladizos. Pero ya sabemos, hoy, que el otro camino es indefendible e intolerable. 